\title{
Antioxidant, Phytotoxic and Antimicrobial Activities of Methanolic Extract of Bauhinia variegata Barks
}

\author{
Khaga Raj Sharma, ${ }^{1,2}$ Surya Kant Kalauni ${ }^{1}$ and Suresh Awale ${ }^{3}$ \\ ${ }^{1}$ Central Department of Chemistry, Tribhuvan University, Kirtipur, Kathmandu, Nepal \\ ${ }^{2}$ Birendra Multiple Campus, Bharatpur, Chitwan, Nepal \\ ${ }^{3}$ University of Toyama, Frontier Research Core for Life Sciences, Toyama 930-0194, Japan \\ EMail-khagaraj_sharma33@yahoo.com
}

\begin{abstract}
Bauhinia variegata is well-known medicinal plant used from the ancient era to till date for their medicinal values. The methanolic extract of Bauhinia variegata barks was screened for phytochemical constituents, antioxidant, phytotoxic and microbial activity. The microbial activity was tested against Staphylococcus aureus, Bacillus subtilis, Escherichia coli and Salmonella typhi at different concentration of 10,15 and $20 \mathrm{mg} / \mathrm{mL}$ by agar well diffusion method. The plant extract showed the potent antimicrobial activity against the Staphylococcus aureus, Salmonella typhi, Bacillus subtilic and Escherichia coli with zone of inhibition $14 \mathrm{~mm}, 12 \mathrm{~mm}, 14 \mathrm{~mm}$ and $11 \mathrm{~mm}$ respectively. Phytochemical analysis of the extract revealed that the antioxidant and antimicrobial activity of the plant materials is due to the presence of active secondary metabolites. In DPPH free radical scavenging assay the $\mathrm{IC}_{50}$ value of Bauhinia variegata was found to be $6.48 \pm 0.08 \mu \mathrm{g} / \mathrm{mL}$, while the $\mathrm{IC}_{50}$ value of the reference standard ascorbic acid was $45.93 \mu \mathrm{g} / \mathrm{mL}$. The extract of Bauhinia variegata, contains high value of phenolic (156.30 $\pm 0.3 \mathrm{mg} \mathrm{GAE} / \mathrm{gm})$ and flavonoid $(16.04 \pm 1.4 \mathrm{mg} \mathrm{QE} / \mathrm{gm})$ content exhibited the high antioxidant activity. The in-vitro phytotoxic bioassay showed $65 \%, 40 \%$, and $25 \%$ growth regulation at just higher conc. of 1000,100 and $10 \mu \mathrm{g} / \mathrm{mL}$ with number of fronds 07,12 and 15 respectively with respect to standard drug Paraquat of concentration $0.015 \mu \mathrm{g} / \mathrm{mL}$.
\end{abstract}

Keywords: medicinal plants, methanolic extract, free radical, phytotoxic, DPPH.

\section{INTRODUCTION}

Plants have been important sources of medicines since beginning of human civilization. Many herbal remedies have been employed in various medicinal systems for treatment and management of different chronic and infectious diseases (Luitel et al. 2014, Pandey et al. 2015). The majority of population in developing country, especially tribal, ethnic groups and mountain people relies on traditional medical practices. In many cases this practice is transmitted orally from generation to generation and confined to certain people (Mishra et al. 2013). Large proportions of world's population depend on traditional medicine because of scarcity, high cost of orthodox medicine and unpleasant side effect. Thus, in the present study we would like to collect the Nepalese medicinal plants Bauhinia variegata from the Syangja district of 1088 meters altitude. The plant species is deciduous tree about $10 \mathrm{~m}$ high. The plant is distributed throughout Nepal at 150-1800 m in open valleys with good loamy soil but generally planted on private land for fodder and as a fuel wood substitute (Nascimento et al. 2011). The plant species have rich in phytoconstituents with high antioxidant value and potent to microbial activity towards gram positive and gram negative bacteria. The oxidation induced by reactive oxygen species (ROS) can result in cell membrane disintegration, membrane protein damage and DNA mutation, which can further initiate or propagate the development of many diseases, such as cancer, liver injury, cardiovascular disease, tumour inflammation, hemorrhagic shock, atherosclerosis, diabetes, infertility, gastrointestinal, ulcerogenesis, asthma, rheumatism and neurodegenerative diseases (Negi et al. 2012). Although the body possesses such defense mechanism, as enzymes and antioxidant nutrients, which arrest the damaging properties of ROS, continuous exposure to chemicals and contaminants may lead to an increase in the amount of free radicals in the body beyond its capacity to control them, and cause irreversible oxidative damage (Divya et al. 2012). Both cigarette smoking and chronic inflammation are of the major causes of cancer have strong free radical components in their mechanism of action. Some research has indicated that people who smoke tend to have lower antioxidant levels than non smokers and are at an increased risk for both cancer and cardiovascular disease. In this respect polyphenolic compounds, like flavonoids and phenolic acids, found in plants have been reported to have multiple biological effects, including antioxidant 
activity (Pahwa et al. 2011). It is generally assumed that frequent consumption of plant derived phytochemicals from vegetables, fruits, tea and herbs may contribute to shift the balance toward an adequate antioxidant status (Sawhney et al. 2011). In the present study, antioxidant potential of the methanol extracts of Bauhinia variegata with $\mathrm{IC}_{50}$ value was found to be $8.05 \pm 1.4 \mu \mathrm{g} / \mathrm{mL}$ as compared to the standard ascorbic acid $45.93 \mu \mathrm{g} / \mathrm{mL}$. by using 1,1-diphenyl-2-picrylhydrazyl (DPPH) free radical scavenging assay.

Infectious disease account for approximately one half of all deaths in tropical countries and they are considered a major threat to human health because of the unavailability of vaccines or limited chemotherapy. Infectious diseases caused by multi-resistant microbial strains are on the increase and fighting these diseases with natural products may be more efficacious (Dhale et al. 2011). The aim of this study is to investigate the in vitro antioxidant and antimicrobial activity of methanolic extracts of Bauhinia variegata barks. The most important bioactive constituents of plants are steroids, terpenoids, carotenoids, flavonoids, alkaloids, tannins and glycosides (Saha et al. 2011). In this study the methanolic plant extract was tested against gram positive and gram negative bacteria and showed higher antibacterial activity against Salmonella typhi, Bacillus subtilic, Escherichia coli and Stayphylococcus aureus. Phytotoxic natural products may be utilized either directly or as lead compounds for the development herbicides (Morimoto et al. 2009). Some wild plants are known to exhibit phytotoxicity by releasing water soluble phytotoxins (Horshy 1977, Sterling 1987). These undesired plants that complete with crop plants for nutrients and produce toxic chemicals which inhibit germination and growth of desired plant (Ghulan et al. 2013).

\section{MATERIALS AND METHOD}

\section{Plant materials}

The plant sample was collected from Syangja district of Nepal based on ethnobotanical uses. The plant was identified by Rita Chhetry, Research Officer, National Herbarium and Plant Resources, Ministry of Forests and Soil Conservation, Godawari, Nepal.

\section{Extraction}

The plant sample was shade dried at room temperature and powdered material was then weighed $(50 \mathrm{~g})$, soaked in methanol for $72 \mathrm{~h}$ and filtered using Whatman No 40 filter paper. The filtrate obtained was concentrated under reduced pressure in a rotatory evaporator to obtain the crude extract.

\section{Phytochemical screening}

Phytochemical analysis of crude methanolic extracts of these medicinal plants was carried out based on the procedure described on the standard protocol (Edeoga et al. 2005).

\section{Antimicrobial activity}

Nutrient agar was added in distilled water in the ratio of $28 \mathrm{~g} /$ litre in appropriate size of conical flasks and boiled with continuous shaking and autoclaved at $121{ }^{\circ} \mathrm{C}$ for 30 minutes. Sterilized media was allowed to cool about $50{ }^{\circ} \mathrm{C}$. These were distributed in the sterile Petri-plates of size of $90 \mathrm{~mm}$ diameter in the ratio $25 \mathrm{~mL}$ per plate aseptically and labeled properly. Plates were left as such for solidification.

The antibacterial of crude extract was employed against the test organisms by agar well diffusion method. Sterile Muller Hinton Agar (MHA) plates of approximately $4 \mathrm{~mm}$ thickness were prepared. Before using the plates, they were dried under hot air oven at appropriate temperature to remove excess of moisture from the surface of the media. The fresh inoculums comparable with turbidity standard were prepared. Then a sterile cotton swab was taken out and was dipped into the prepared inoculums. The excess of inoculums was removed by pressing and rotating against the upper inside side wall of the tube above the liquid level and then swabbed carefully all over the plate. The plate was rotated through the angle of $60^{\circ}$ after each swabbing. Finally the swab was passed round the edges of the agar surface. The inoculated plates were left to dry for few minutes at room temperature with the lid closed. Then with the help of sterile cork borer no 5, wells were made in the inoculated media plates and labeled properly. So, the diameter of a well was 6 $\mathrm{mm}$. Then $50 \mu \mathrm{L}$ of the plant extract was introduced into respective well. In one well pure methanol was filled as control. The plates were then left for half an hour with the lid closed so that the extract diffused into media. The plate was incubated overnight at $37{ }^{\circ} \mathrm{C}$. After proper incubation (18-24 hours) the plates were observed for the zone of inhibition around well (Farrukh et al. 2010, Nucrat et al. 2006, Rao et al. 2008).

\section{Antioxidant activity test (DPPH radical scavenging assay)}

The free radical scavenging activity was measured by using DPPH assay. Different concentration of test samples $(5,10,20,30,40,50,60,70,80,90,100 \mu \mathrm{g} /$ $\mathrm{mL}$ ) were prepared while the concentration of DPPH was $0.2 \mathrm{mM}$ in the reaction mixture. These reaction mixtures were taken in Eppendorf tubes and incubation at $37{ }^{\circ} \mathrm{C}$ for $30 \mathrm{~min}$. Discolorations were measured at $517 \mathrm{~nm}$ using a UV-Visible Spectrophotometer. Percent radical 
scavenging activity by sample treatment was determined by comparison with methanol treated control group; ascorbic acid was used as positive control. Measurement was performed at least in triplicate. The percentage scavenging of the DPPH free radical was calculated using the following equation (Yerra et al. 2008, Jondaity et al. 2005, Pani et al. 2011).

$\%$ Scavenging $=\frac{\text { Abs. control - Abs. sample }}{\text { Abs.control }} \times 100$

The inhibition curve was plotted for the triplicate experiments and represented as percentage of mean inhibition \pm standard deviation and the $\mathrm{IC}_{50}$ values was obtained.

\section{In-vitro Phytotoxicity bioassay}

E-Medium was prepared by mixing various constituents in $1000 \mathrm{ml}$ distilled water and $\mathrm{pH}$ was adjusted between 6.0 to 7.0 by adding $\mathrm{KOH}$ pellets (Stock solution). Working E-medium was prepared by mixing $100 \mathrm{~mL}$ of stock solution and $900 \mathrm{ml}$ of distills water. $30 \mathrm{mg}$ for crude extract was dissolved in $1.5 \mathrm{ml}$ of solvent methanol serving as stock solution. Three flasks were inoculated with 10,100 and $1000 \mu \mathrm{L}$ of solution pipette from the stock solution for 10,100 and $1000 \mu \mathrm{g} / \mathrm{ml}$ solvent was allowed to evaporate overnight. $20 \mathrm{~mL}$ of working E. medium was added and then plant of Lemna minor, each containing a rosette of two to three fronds, to each flask. (total 20 fronds). Other flasks supplemented with E-medium and reference (standard drug) plant growth inhibitors and promoters serving as negative and positive controls, respectively. The flaks were placed in growth cabinet for seven days. Plants were examined daily during incubation. Number of fronds per flasks were counted and recorded on day seven. Results were analyzed as growth regulation in percentage, calculated with reference to the negative control (Rehmanullah et al. 2014).

\section{RESULTS AND DISCUSSION}

Phytochemiccal screening result showed that, plant extract was rich source of secondary metabolites like polyphenols, alkaloids, flavonoids, steroids, and tannin except, reducing sugars, terpenoid, glycosides and saponins.

Table 1. Phytochemical analysis of plant extracts

\begin{tabular}{|l|l|l|l|}
\hline Polyphenols & + & Reducing sugar & + \\
\hline Steroids & - & Tannin & + \\
\hline Alkaloids & + & Cardiac glycoside & + \\
\hline Flavonoids & + & Anthraquinone & + \\
\hline Terpenoids & - & Carotenoids & + \\
\hline Glycosides & - & Saponin & + \\
\hline
\end{tabular}

Key: $+=$ Present $\quad-=$ Absent

The plant extracts containing secondary metabolites are known to be biologically active and therefore, aid the antimicrobial activities through different mechanism. The antibacterial activity of plant bark extract was assayed invitro by agar disc diffusion and agar well diffusion method against four bacterial species. Steroidal compounds present in plant extract are of importance due to their relationship with various anabolic hormones including sex hormones. Flavonoids and their constituents exhibited a wide range of biological activities like antimicrobial, anti-inflammatory and antioxidant properties. It is concluded that the plant extract is a potential source of active antimicrobial agents against the tested bacterial species. The inhibition of these plant extracts against pathogenic bacterial strains can introduce the plant as a potential candidate for drug development for treatment of ailments caused by these pathogens.

Table 2. Antimicrobial activity of plant extract

\begin{tabular}{|c|c|c|c|c|c|}
\hline \multicolumn{6}{|c|}{ Zone of inhibition (ZOI), $\mathrm{mm}$} \\
\hline Plant extract & Concentration & Stayphylococcus aureus & Bacillus subtilic & Salmonella typhi & E.Coli \\
\hline \multirow[t]{3}{*}{ Bauhinia } & $10 \mathrm{mg} / \mathrm{mL}$ & 12 & 11 & 10 & 10 \\
\hline & $15 \mathrm{mg} / \mathrm{mL}$ & 14 & 12 & 10 & 11 \\
\hline & $20 \mathrm{mg} / \mathrm{mL}$ & 14 & 14 & 11 & 11 \\
\hline
\end{tabular}

Table 3. In-vitro Phytotoxic bioassay

\begin{tabular}{|c|c|c|c|c|c|}
\hline Name of the plant & $\begin{array}{l}\text { Conc. of Plant extract } \\
(\mu \mathrm{g} / \mathrm{mL})\end{array}$ & \multicolumn{2}{|c|}{ No. of fronds } & $\%$ Growth Regulation & $\begin{array}{c}\text { Conc. of } \\
\text { Standard Drug }(\mu \mathrm{g} / \mathrm{mL})\end{array}$ \\
\hline \multirow{3}{*}{ Lemna minor } & 1000 & 07 & \multirow[b]{3}{*}{20} & 65 & \multirow[b]{3}{*}{0.015} \\
\hline & 100 & 12 & & 40 & \\
\hline & 10 & 15 & & 25 & \\
\hline \multicolumn{6}{|c|}{ Keys: Std. Drug Paraquat $\quad$ Incubation Condition $=\left(28^{\circ} \pm 1 C^{\circ}\right)$} \\
\hline
\end{tabular}




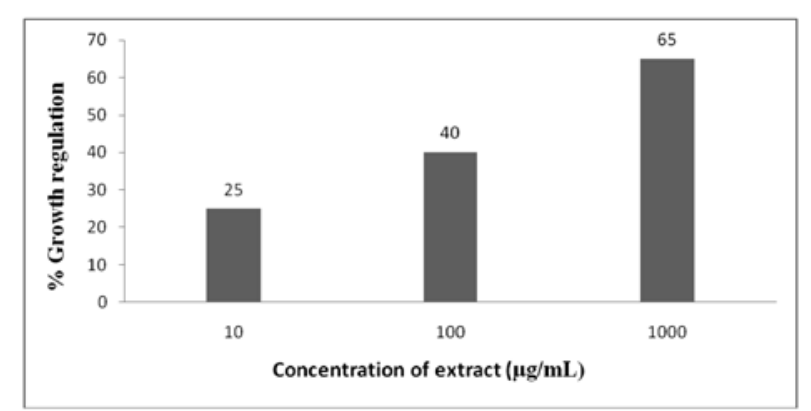

Fig. 1. Phytotoxic activity of different concentration of Bauhinia variegata

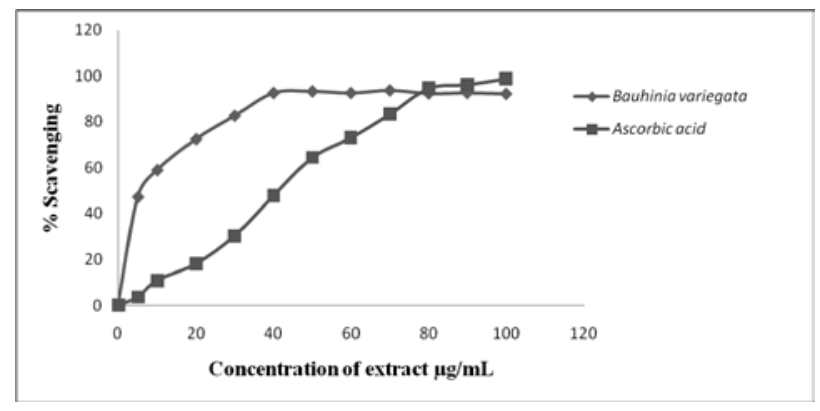

Fig. 2. Percentage scavenging of DPPH free radical with different concentration of plant extracts

Antioxidants may offer resistance against oxidative stress by scavenging the free radicals inhibiting lipid peroxidation etc. Antioxidants can act by converting the unpaired electrons to paired ones. The dose dependent inhibition of DPPH radical indicates that plant extract causes reduction of DPPH radical in a stoichiometric manner. The present study was carried out to analyze the antioxidant activity of the methanolic plant extracts. The plant extract of Bauhinia variegata is the source of potent antioxidant with the strongest DPPH radical scavenging activity $\left(\mathrm{IC}_{50}=6.48 \pm 0.08 \mu \mathrm{g} / \mathrm{mL}\right)$ whereas standard ascorbic acid has $\mathrm{IC}_{50}$ of $45.93 \mu \mathrm{g} / \mathrm{mL}$. The result showed significant total phenolic and flavonoid content in plant extract. The extract of Bauhinia variegata, contain high value of phenolic (156.30 $\pm 0.3 \mathrm{mg}$ GAE/gm) and flavonoid content $(14.04 \pm 1.4 \mathrm{mg}$ QE/gm) exhibited the greatest antioxidant activity.

Bioactivity studies of two species of mimosa species showed prominent antioxidant activity. methanol extract of the bark of Machilus odoratissima exhibited high free radicals scavenging activity (Amit et al. 2012). In our study, the antioxidant capacity of this medicinal plant extract could be compared with the results of previously studied plant extract. The antioxidant capacities in $\mathrm{mg}$ ascorbic acid per gram for plants were Thymus vulgaris
(0.6 \pm 0.3$)$, Lavandula vera $(0.6 \pm 0.4)$, Rosmarinus officinalis (0.5 \pm 0.1$)$, Origanum dictamnus $(0.2 \pm 0.2)$, Sideritis cretica $(0.8 \pm 0.1)$, Salvia officinalis $(0.4 \pm 0.1)$ and Origanum vulgare $(0.3 \pm 0.1)$. The result suggested that the plants extract studied in this work is the potent source of antioxidants in comparison to previous results (Zorica et al. 2009, Rehmanullah et al. 2014).

Table 4. DPPH scavenging $\left(\mathrm{IC}_{50}\right)$ value, total flavonoid and total phenolics content

\begin{tabular}{|l|c|}
\hline Total flavonoid content & $14.57 \pm 1.4 \mathrm{mg} \mathrm{QE} / \mathrm{gm}$ \\
\hline Total phenolic content & $156.30 \pm 0.3 \mathrm{mg} \mathrm{GAE} / \mathrm{gm}$ \\
\hline DPPH scavenging $\left(\mathrm{IC}_{50}\right)$ & $6.48 \pm 0.08 \mu \mathrm{g} / \mathrm{mL}$ \\
\hline
\end{tabular}

\section{CONCLUSIONS}

DPPH scavenging activity showed that the methanolic extract possesses the antioxidant property. The plant extract is the potent antioxidant with DPPH scavenging $\mathrm{IC}_{50}=6.48 \pm 0.08 \mu \mathrm{g} / \mathrm{mL}$ with respect to the standard ascorbic acid of $\mathrm{IC}_{50}$ of $45.93 \mu \mathrm{g} / \mathrm{mL}$. Phenolic compounds and flavonoids have been reported to be associated with antioxidative action in biological system, acting as scavengers of singlet oxygen and free radicals. Antimicrobial assay of different concentration showed their activity towards tested organisms and found to be most biologically active. Among the tested organisms, the plant extract showed the highest ZOI $(14 \pm 0.1 \mathrm{~mm})$ for Staphylococcus aureus. Similarly the plant extract showed the potent activity towards the organism like Bacillus subtilic, Salmonella typhi and Escherichia coli with ZOI $14 \pm 0 \mathrm{~mm}, 11 \pm 0 \mathrm{~mm}$ and $11 \pm 0 \mathrm{~mm}$ respectively. The sample showed moderate phytotoxic activity $65 \%$, $40 \%$ and $25 \%$ growth regulation with number of fronds 07,12 and 15 respectively which is comparable to the standard drug paraquat with number of fronds 20 at a concentration of $0.015 \mu \mathrm{g} / \mathrm{mL}$.

\section{ACKNOWLEDGEMENTS}

The authors are thankful to Rita Chhetry, National Herbarium and Plant Resources, Ministry of Forests and Soil Conservation, Godawari, for identification of plant. The authors are grateful to the Central Department of Chemistry, Central Department of Biotechnology, Central Department of Microbiology, Tribhuvan University for providing laboratory facilities; Nepal Academy of Science and Technology (NAST) for partial financial support to Mr. Sharma, and HEJ research Institute of Chemistry, ICCBS, University of Karachi Pakistan for providing laboratory facilities for in-vitro phytotoxic bioassay. 


\section{REFRENCES}

Amit S., Mohan, P.A. Tirtha, M.S. Shyam, K.M. Bharat M. P. 2012. Antioxidant and antibacterial activity of methanolic extract of machilus odoratissima. Kathmandu University Journal of Science, engineering and technology 8(1): 73-80.

Dhale, D.A. 2011. Phytochemical screening and antimicrobial activity of Bauhinia variegata Linn. Journal of Ecobiotechnology 3(9): 04-07.

Divya, D., Anita, P. 2012. Antimicrobial, phytochemical and antioxidant assay of Bauhinia variegata (Kachnaar) extracts against some pathogenic microbes. Research Journal of BioTechnology 7(4): 212-216.

Dondaity, S.E., Mahdy, M. Hamouly, M. Ammar, H. 2005. Chemical and/or biological studies of Bauhinia variegata L. and Cleome droserifolia (Forssk.) Del. growing in Egypt. Egyptian Journal of Biomedical Sciences 19: 181-203.

Edeoga, H., Okwu, D.E. Mbaebie, B.O. 2005. Phytochemical constituents of some Nigerian medicinal plants. African Journal of Biotechnology 4 (7): 685-688.

Farrukh, H., Ishfaq, H. Ghula, D. Sharms, N. Ibrar, K. Bashir, A. 2010. Cytotoxicity and phytotoxicity of some selected medicinal plants of family polygonaceae. African Journal of Biotechnology 9(5): 770-774.

Ghulam, D., Farrukh, H. 2013. Phytotoxic and Insecticidal activity of plants of family zygophyllaceae and euphorbiaceae. Sarad Journal of Agriculture 29(1): 83-91.

Luitel, D.R., Rokaya, M.B. Timsina, B. Münzbergova, Z. 2014. Medicinal plants used by the Tamang community in the Makawanpur district of central Nepal. Journal of Ethnobiology and Ethnomedicine 10(5).

Mishra, A., Sharma, A.K. Kumar, S. Saxena, A.K. Pandey, A.K. 2013. Bauhinia variegata leaf extracts exhibit considerable antibacterial, antioxidant, and anticancer activities. Biological Medical Research International 915436, 11.

Nascimento, J.C., Lage, L.F.O. Camargos, C.R.D. Amaral, J.C.C. Lucas, M. Nascimento, S. Adriana, O. Francielda, Q. 2011. Antioxidant determination activity by the DPPH method and assay for total flavonoids in leaf extracts of Bauhinia variegata L. Revista Brasileira de Farmacia 92(4): 327-332.

Negi, A., Sharma, N. Pant, R. Singh, M.F. 2012. Determination of total phenolic content of the stem bark of Bauhinia variegata Linn. an approach to standardization. Pharma Research 7(2): 16-22.
Nucrat, J., Modassir, I. Arsala, M. Asma, Y. 2006. Phytotoxicity and Acropitilon repens (Asteraceae) and Nepeta pretervisa (Laminaceae). Journal of Applied Ethnomedicinal Science 2(3): 164-166.

Pahwa, S., Mazumder, R. Bhattacharya, S. 2011. Evaluation of in vitro antimicrobial activity of different parts of Bauhinia variegata Linn. International Journal of Pharmaceutical Technology Research 3(4): 1971-1977.

Pandey, S., 2015. Preliminary phytochemical screening and in vitro antibacterial activity of Bauhinia variegata Linn. against human pathogens. Asian Pacific Journal of Tropical Disease 5(2): 123-129.

Pani, S.R., Mishra, S. Sahoo S. Panda, P.K. 2011. Nephroprotective effect of Bauhinia variegata (Linn.) whole stem extract against cisplatininduced nephropathy in rats. Indian journal of pharmacology 43(2): 200-2.

Rao, Y.K., Fang, S. Tzeng, Y. 2008. Antiinflammatory activities of flavonoids and a triterpene caffeate isolated from Bauhinia variegata. Phytotherapy Research 22(7): 957-962.

Rehmanullah, Siraj, D., Sumaira, S. Zahir, M. 2014. Pharmacological evaluation of Euphorbia helioscopia L. and Euphorbia hirta L. International Journal of Biosciences 4(1): 20-26.

Rehmanullah, S.D., Sumaira, S. Zahir, M. 2014. Pharmacological evaluation of Euphorbia helioscopia L. and Euphorbia hirta L. International Journal of Biosciences 4(1): 20-26.

Saha, S., Subrahmanyam, E.V.S. Kodangala, C. Shastry, S.C. 2011. Isolation and characterization of triterpenoids and fatty acid ester of triterpenoid from leaves of Bauhinia variegata. Pharma Chemica 3(4): 28-37.

Sawhney, S.S., Mir, M. A. Kumar, S. 2011. Phytochemical screening and antioxidant properties of Bauhinia variegata (bark). Journal of Pharmaceutical Science \& Technology 3(8): 645-650.

Yerra, K., Fang, S., Tzeng, Y. 2008. Antiinflammatory activities of flavonoids and a triterpene caffeate isolated from Bauhinia variegata. Phytotherapy Research 22(7): 957-962.

Zorica, H., Hatidza, P. Albina, M. Majda, S. Mirzeta, S. 2009. The Influence of total phenols content on antioxidant capacity in the whole grain extract. European Journal of Scientific Research 28(3): 471-477. 